\title{
REVIEW
}

\section{A Study on the Effectiveness of Chinese Farmers' Participation under the Background of Rural Rejuvenation}

\section{Quanhai Yang*}

Chongqing Medical University, Chongqing, 400016, China

\begin{tabular}{|c|c|}
\hline ARTICLE INFO & ABSTRACT \\
\hline $\begin{array}{l}\text { Article history } \\
\text { Received: } 26 \text { March } 2020 \\
\text { Revised: } 2 \text { April } 2020 \\
\text { Accepted: } 9 \text { April } 2020 \\
\text { Published Online: } 16 \text { April } 2020 \\
\text { Keywords: } \\
\text { Farmers } \\
\text { Political participation } \\
\text { Democratic consciousness }\end{array}$ & $\begin{array}{l}\text { The strategy of Rural Revitalization is an important strategic measure to } \\
\text { comprehensively promote rural modernization in the period of building a } \\
\text { socialist modernization country with Chinese characteristics. In essence, } \\
\text { a farmer's political participation is, of course, to inevitably build a new } \\
\text { socialist countryside, cultivate new socialist farmers and realize socialist } \\
\text { rural modernization. This paper attempts to explore the promotion and } \\
\text { efficient realization of farmers' political participation from three ways of } \\
\text { improving the subject ability of political participation, first, to improve } \\
\text { subject ability; second, to guarantee object conditions, third, and to create } \\
\text { the proper environment. And this paper illustrates that the modernization } \\
\text { of rural areas requires the modernization of farmers' ideology and politi- } \\
\text { cal consciousness. The comprehensive promotion of the modernization of } \\
\text { peasants' ideology and political consciousness is embodied in the practice } \\
\text { of political participation. }\end{array}$ \\
\hline
\end{tabular}

\section{Introduction}

I n the strategic plan for Rural Revitalization (2018 2022), it is pointed out that "adhere to the dominant position of farmers" and "improve the participation of farmers". The main position and participation degree of farmers are not only reflected in the behavior of economic production, but also the practice of political participation. Huntington thinks that political participation is "the activity that the common people try to influence the government's decision-making" ${ }^{[1]}$. Because of the current situation that the degree, level, and quality of political participation of farmers in China are not high, it is of great significance to explore the focus of this participation of the farmers in China and find the correct path foe the farmers, to improve the quantity and quality of political participation of farmers, and to strive to achieve political civilization in China, especially in rural areas.

\section{The Improvement of Farmers' Ability of Participation}

As the main body of rural political participation, farmers must have the corresponding quality and ability. To cultivate and improve their quality from the aspects of participative consciousness, knowledge and ability is one of the key factors for farmers to give full play to their subjective initiative of political participation. The promotion of participative consciousness is the ideological guarantee of peasants' participation. For a long time, affected by the traditional Chinese feudal political culture, it restrained the farmers' subjectivity and enthusiasm, and their partic-

*Corresponding Author:

Quanhai Yang,

Chongqing Medical University, Chongqing, 400016, China;

E-mail:929999811@qq.com. 
ipative consciousness was indifferent. From the aspects of democracy, law and decision-making consciousness of farmers, we can promote the awareness of the political participation of farmers.

\subsection{The Promotion of Farmers' Democratic Con- sciousness}

A free and democratic life is the way to material prosperity. ${ }^{[2]}$ The key to strengthening the peasants' democratic consciousness lies in abandoning the feudal traditional ideology, cultivating the modern citizen consciousness and high political enthusiasm, cultivating the spirit of the country's master, and actively participating in the country's political decision-making. We should get rid of the feudal autocratic ideology, which has been influenced for thousands of years and strive to cultivate the modern democratic consciousness and spirit. By re-examining the traditional feudal autocratic political culture in China, we should study and understand the concept of democracy in modern society.

\subsection{The Improvement of Farmers' Legal Con- sciousness}

Law is a set of abstract rules about justice that condenses the community ${ }^{[3]}$.The enhancement of farmers' legal consciousness is strong support to improve farmers' awareness of political participation. To realize the organic combination of the rule of law and the rule of a village by law, the degree of the rule of law in rural areas and the legal consciousness of farmers play an important role in the development the enhancement of the consciousness of political participation of farmers. To strengthen the farmers' legal consciousness, we must let them actively participate in the activities of popularizing the law in rural areas, learn the knowledge of laws and regulations, strive to make everyone in rural areas learn the law, know the law, abide by the law and use the law. In practice, we should take the initiative to protect our political rights and interests with legality.

\subsection{The Enhancement of Farmers' Decision-Mak- ing Consciousness}

The development of the farmers is related to the development of the country and the improvement of the decision-making ability of the country is related to the future and destiny of the development of the country. Therefore, farmers should fully realize that participating in national political decision-making, the formulation of national major policies is a matter of vital interest for farmers. Because "the countryside is not only a regional concept but also a political concept. Farmers are not only a professional identity but also a policy identity." ${ }^{,[4]}$ Therefore, farmers should cultivate a sense of active participation in local government political decision-making.

\subsection{The Cultivation of Teamwork Ability}

Farmers' participation in national government decision-making requires team consciousness, team spirit, and team cooperative ability. Because the declaration of policies in line with the actual situation of a village or town is the crystallization of the collective wisdom of all members of the whole village or town ${ }^{[5]}$. Collective discussion and collective decision-making should be carried out when major policies are related to the development of the whole village and town and the vital interests of farmers. At the same time, we often organize and carry out some collective competitions and activities to enhance farmers' sense of team cooperation and the ability of unity and cooperation.

\subsection{The Cultivation of Insight}

Political decision-making requires political participants to have some insight into current affairs. Only with the certain ability of political and current affairs insight, can farmers catch some new information and situations related to local political decision-making everywhere, so that in participating in political decision-making, they can put forward practical and effective decision-making proposals according to local reality and development needs.

\subsection{Cultivation of Organizational Ability}

Organizational capacity is an important factor in determining the efficiency of the political participation of farmers. The stronger the organizational capacity of farmers is, the more opportunities they have to participate in politics. To cultivate the organizational ability of farmers, we can establish trade union organizations, Communist Youth League organizations, service associations, supervision associations and other rural groups in rural areas to cultivate the organizational ability of farmers.

\section{The Object of Participation: Shaping the Good Image of the Government}

As the object of the government to mobilize farmers as the main participants to actively participate in the decision-making of local political affairs, brainstorming, we must shape a good social image.

\subsection{Enhance the Authority of Local Government}

The authority of the government always affects the trust 
of the masses. To be able to enhance the authority of the government we must, first of all, establish a practical and effective power operation system to ensure the effective implementation of power. Secondly, we need to cultivate high-level and high-quality managers to ensure that power is exercised for the benefit of the people. Once the government of the people, by the people, for the people, the farmer will actively participate the government decision-making.

\subsection{Improve Government Credibility}

The credibility of the government determines the people's trust, recognition, and participation in the government. To establish the credibility of the government, first of all, the purpose of the government's political decision-making must be based on the fundamental interests of the farmers, and establish the idea of serving the farmers. Secondly, the government should respect the will of farmers before making any decision, and reflect the will of farmers. Finally, the local government's public affairs management behavior and the activity must solve the farmer's actual problem and the difficulty earnestly.

\subsection{The Creation of a Good Hard and Soft Envi- ronment}

Farmers' political participation must be guaranteed by an appropriate environment. Starting from the general environment of the whole society and focusing on the hardware environment, cultural environment, and institutional environment, we should create an in-depth and accurate environment for farmers' political participation.

\subsubsection{Improve the Hardware Environment of Farmers' Political Participation}

Modern democratic consciousness and political participation consciousness are based on a certain level of economic development. Because "in a society, the level, form, and basis of political participation are closely related to the level of socio-economic development. A high level of political participation is always accompanied by a higher level of development." ${ }^{,[6]}$ The level of economic development is closely related to the level of political participation. The higher the level of social and economic development, the higher the level of political participation will be. We can achieve this by, first of all, ensuring the stability of the land as the source of farmers' life, because most of the economic sources of farmers come from the land. Secondly, we should strengthen the construction of rural infrastructure because the improvement of a rural education level is based on the construction and completion of educational and cultural infrastructure.

\subsubsection{Improve the Modern Information Network Technology in Rural Areas}

With the development of national social economy, the influence of modern information network on the life of farmers is increasingly important. Therefore, the local government should strengthen the construction of modern information technology in rural areas, and improve the construction and improvement of modern information transmission tools such as television, radio, newspapers and magazines, and postal services. These technological advances can apply to modern government management, establish e-government, enhance the function of government online, facilitate the effective and quick handling of rural affairs, and facilitate the political and social communication of farmers. The interactivity of modern information networks makes the majority of farmers turn from the original "audience" to "interlocutor".

\section{Smooth the channels of farmers' Political Participation}

Local governments ensure the smooth channels of farmers' political participation in various ways. First of all, they ensure the realization of the political election activities of farmers. A political election is an important manifestation of farmers' political participation and the main channel of their political participation. Secondly, to ensure the realization of political contact activities of farmers. Farmers' political contact means that farmers directly or indirectly reflect the situation, put forward suggestions, opinions or criticisms to local government leaders in the form of individuals or organizations, and participate in the decision-making of local government.

\subsection{Perfecting the System Environment of Peas- ants' Political Participation}

People's opinions come from their system ${ }^{[7]}$. The level and extensiveness of peasants' political participation are fundamentally determined by the security and stability of the institutional environment. Therefore, we must improve the mechanism of rural farmers' political participation, dredge the channels of participation, and constantly promote the institutionalization, legalization and procedural construction of farmers' political participation.

\subsection{Strengthen the Construction of Democratic Political System}

First, to encourages and guides the farmers to participate 
in the local decision-making through institutionalization, to play the role of the democratic self-government system of rural grass-roots masses in self-education, self-service, self-management and other aspects of farmers. Second, we should combine the construction of a rural grassroots democratic political system with the economic development of the region, so that farmers can truly realize democratic decision-making, democratic management, and democratic supervision. Third, democratic election, decision-making, and management should be carried out in all rural affairs.

\subsection{Improve and Perfect the Democratic Supervi- sion Mechanism}

Democratic supervision is an important content stipulated in the organization law of the villagers' committee of the People's Republic of China. It is also an important guarantee for farmers to supervise various undertakings in rural areas according to law and is directly related to the enthusiasm and initiative of farmers' political participation.

We should establish a system of open village affairs, open financial system, democratic appraisal system, cadre responsibility system, and cadre accountability system, "so that farmers can fully know the government, and create conditions for strengthening the supervision of farmers." ${ }^{[8]}$. In this way, we should establish a perfect supervision and restraint mechanism for the power operation of village cadres, ensure the effective supervision of village cadres by farmers, enhance the confidence of farmers in participating in politics and stimulate their enthusiasm.

\section{Conclusion}

The strategy of rural rejuvenation is a strategic decision made by China for the development of rural modernization. First, through the promotion of farmers' democratic consciousness, legal consciousness and decision-making consciousness, the awareness of farmers' political participation will be enhanced, and the ability of farmers' organization, insight and cooperation will be enhanced. Second, farmers' active participation in politics is conducive to enhancing the authority, credibility and sense of responsibility of the government. Third, the government should improve the rural hardware and software environment, and then we can more effectively realize the political participation of farmers, safeguard their own rights and interests, and promote the modernization of rural areas.

\section{References}

[1] Huntington, S.P., et al., hard to choose: political participation of developing countries [M]. Translated by Wang Xiaoshou, et al., Beijing: Huaxia press, 1989:3.

[2] Francis Fukuyama, the end of history [M]. Translation group of this book, Hohhot: distance publishing house, 1998:232.

[3] [US] Francis Fukuyama, the origin of political order: from the pre human era to the French Revolution [M]. Translated by Mao Junjie, Guilin: Guangxi Normal University Press, 2014:246.

[4] Xia Yong. Towards the age of rights [M]. Beijing: China University of political science and Law Press, 2000:616.

[5] Du Jiangxian. Some problems on the reputation of Chinese government [J]. Shandong Social Sciences, May 2003.

[6] Huntington, S.P., et al., hard to choose: political participation of developing countries [M]. Translated by Wang Xiaoshou, et al., Beijing: Huaxia press, 1989:174.

[7] Rousseau, social contract theory [M]. Translated by Li Pingou, Beijing: Commercial Press, 2011:142.

[8] Wang Wei. Building a harmonious society in expanding citizens' political participation $[\mathrm{J}]$. Hunan Social Sciences, April 2006. 